\title{
Mathematical Modeling of An Industrial Firm in Transient Economy
}

\author{
I.G. POSPELOV \\ Computing Center of RAS, Russia
}

\begin{abstract}
A behavior model of an industrial firm with a possibility of merchandising and purchasing of production on two channels, traditional and commercial, is given. The former is stable, but less profitable due to non-payments. The latter is profitable, but risky. The model describes different modes of firm operation depending on economic parameters. In such a model, firms have incentives to integrate in financial and industrial groups.
\end{abstract}

Keywords: Commercial; Maximization; Organization; Russian economy

\section{INTRODUCTION}

The relatively stable state of the Russian economy in 1995-1998 looks somewhat strange from the point of view of mainstream economic theory. The state is characterized by permanent, but not rapid, decrease in production, the coexistence of several types of money, unusual functions of banks in conditions of lack of investments, and low profitability of production (Guriev and Pospelov, 1997).

In the present paper, we offer a description of the activity of a firm which attempts to promote its production in the market, but often fails and even when successful, bears substantial transaction costs. This results in serious problems with the working capital of the firm. When such firms form a majority, they could try to solve their problems by an inter-firm market with special prices. The model logically includes the non-payments and promissory notes circulation as special types of money. The model also displays the essential role of fixed costs and also explains the tendency for spontaneous integration of firms under the aegis of banks in a certain similarity to financial-industrial groups (FIGs). The model, such a FIG, is the kernel of the model of regional economy explained by Avtukhovich et al. (1999).

The problem of the non-payments is the center of attention for Russian and Western economists who are interested in transition economy appearance. The scales and reasons of origin of the non-payments are considered by Shmelev (1997) and Smirnov (1997). In Nonpayments in Russian Economy (1998), the case study of debts is carried out from the point of view of the financial state of a firm. In Klepach (1997), the possibility of struggle with the non-payments is considered through implantation of a system of circulation of promissory notes. It is also necessary to note Makarov and Leiner (1997), who consider the role of barter in modern Russian economy. From the point of view adopted here, barter and the non- 
payments fulfill similar functions, creating additional possibilities for decreasing transaction costs (including expenditures on fulfilling liquidity constrains).

Many fewer publications are devoted to the nonpayments within the framework of formal models. We can point out only Perotti (1994), Pospelov (1995), Kirn and Kwon (1995), Grunville (1996) and Grigoriev (1997). The authors all in their own way attempt to answer a problem: why a firm prolongs delivering production, knowing that it will not be completely paid. Papers (Perotti, 1994; Pospelov, 1995) consider the situation of the first years of an economic reform in Russia, when the firms relied on the state preferential credits and stored the nonpayments as a justification of their getting them. In Kirn and Kwon (1995) and Grunville (1996), the model of a general equilibrium in economy with the non-payments was proposed. In Grigoriev (1997), the non-payments are parsed from the micro-economic point of view - the model of interaction of the buyerseller with the asymmetrical information is considered. In Perotti (1994), Kirn and Kwon (1995), Pospelov (1995), Grunville (1996) and Grigoriev (1997), the equilibrium with the non-payments turns out to be effective.

In the present work, we do not consider a general equilibrium model, parsing behavior of a firm with a system of non-payments. However at the end of the work, we show some reasons why, on the basis of the offered model, it is possible to construct model of a macro-economic equilibrium with the non-payments. Besides, we pay special attention to an economy with fixed costs and show that in this case, a system with the non-payments is more preferable.

\section{MODEL OF INDUSTRIAL FIRM WITH TWO CHANNELS OF DELIVERING}

Let us consider an industrial firm producing homogeneous goods. As the factors of production, we shall take into account only material working capitals (raw material and components). Such a description meets the present state of affairs in the Russian economy, where the manpower in industry is surplus and the fix capital practically does not vary. We consider a stationary model of the activity of a firm, thus first excepting investments (that also conforms to an observable reality).

The technological possibilities of such firm are described by the cost function $\nu=\psi(x)$, where $\tilde{\sigma}$ is gross output, and $\nu$ is material input per unit of time. As we will research only the financial state of the firm (income, cost, profits, and credits) under given constant prices, both input and output may be assumed to be scalars. Suppose that the cost function $\psi(x)$ is defined for all $\tilde{o}>0$, is monotonic, strictly concave, $\psi^{\prime}(x)=0, \psi^{\prime}(\infty)=\infty, \psi(0)>0$. (Usually it is supposed $\psi^{\prime}(0)=0$, but we shall pay special attention to the role of stationary values of costs, $\psi(0)$.)

Our main supposition is that the firm has two channels to purchase raw material and to deliver output. The first channel we will refer to as "traditional", the second as "commercial".

1. The traditional channel corresponds to delivery by the direct inter-firm links, according to the firm's specialization in the Soviet economy. Investigative data (Dologopyatova, 1995; Yakovlev, 1996) show that direct links cover about 75$85 \%$ of delivery. To the traditional channel, we also refer delivering production to the government. We assume that the traditional channel is characterized by the following properties.

- The delivery by direct links is stable: the firm can choose levels of delivery and purchasing on the traditional channel, but once chosen, these levels should be maintained long enough (always within the framework of the model).

- Delivery and purchasing on direct links allow and even estimate the non-payments. As in Pospelov (1995), we consider the nonpayments as a special type of money with a particular system of the prices. For production sold by the firm and raw material expended, we denote these prices by $\delta_{1}$ and $\delta_{2}$ for production of the firm and raw material, respectively. These prices have the 
following meaning: if a market price of production is $q_{1}$, then unit of goods delivered through the traditional channel gives the firm $q_{1}-\delta_{1}$ units of money and increments its accounts by $\delta_{1}$. Similarly, if $q_{2}$ is the market price of raw material, the firm pays only $q_{2}-\delta_{2}$ in money and increments its accounts by $\delta_{2}$.

2. Commercial channel. In present conditions, the majority of industrial firms tend to adapt to the market: the firms search for new types of production (sometimes more primitive than the main one), which can be sold for "live" money. In general, these attempts could hardly be considered to be successful. Therefore, we describe outcome of such attempts as a stochastic process. In the model, this risky commercial channel is characterized by the following properties.

- The firm does not always have a possibility of sales through the commercial channel. This possibility comes and goes at random, i.e. in each moment of time, the firm can be in one of two states: $O$, when it can use only the traditional channel and $C$, when it delivers production on both channels. The state $T$ turns into the state $C$ with frequency $\lambda$ and $C$ turns into $T$ with frequency $\mu$. Thus, the average time which the firm spends in the state $C$ equals $\tau=\lambda /(\lambda+\mu)$.

- The purchasing of raw materials through the commercial channel are paid at market price $q_{2 .}$

- It is known that the industrial firms in Russia have acquired a great many intermediaries and that the trade margin in the Russian economy is held on a high enough level. So we assume that delivering through the commercial channel $Z$ units of good per unit of time, the firm gains only $q_{1} Z-\varphi(Z)$, where $\varphi(Z)$ is the strictly convex selling cost function $\left(\varphi(0)=0, \varphi^{\prime}(0)=0 . \varphi^{\prime}(\infty)=\infty\right.$, $\left.\varphi^{\prime \prime}(Z)>0\right)$. The convexity of $\varphi(Z)$ reflects the fact that an unexpectedly arisen need to sell a major batch of production pushes specific selling costs above the level corresponding to stable sales of small batches.

Thus, the traditional channel may supply the firm with cheap raw materials and admit low-profit, but stable, sales of its product. The commercial channel is on average more profitable, but unstable. Note that we do not suppose any quotas on sales through the commercial channel. Even at small $\tau$, the firm can store its product in the state $T$ and implement large average sales $\tau Z$ through the commercial channel in the state $C$. Since the firm may ignore the commercial channel when it is available, the state $C$, when the commercial channel is open, is at any rate not less preferable than state $O$, when the commercial channel is unavailable.

Let us move on to a formal description of activity of the firm. Denote by $Q_{1}$ and $Q_{2}$ a store of finished product and raw materials, respectively. Then

$$
\begin{gathered}
\mathrm{d} Q_{1} / \mathrm{d} t=x_{T}-Y \quad \text { in } T \\
\mathrm{~d} Q_{2} / \mathrm{d} t=x_{C}-Y-Z \quad \text { in } C
\end{gathered}
$$

where $Y$ denotes delivery through the traditional channel, not depending on state, $Z$ denotes delivery through the commercial channel, and $x_{T}$ and $x_{C}$ are levels of the firm's production in the states $T$ and $C$, respectively.

$$
\begin{gathered}
\mathrm{d} Q_{2} / \mathrm{d} t=-v_{T}+V \quad \text { in } T \\
\mathrm{~d} Q_{2} / \mathrm{d} t=-v_{C}+V+W \quad \text { in } C
\end{gathered}
$$

where $V$ denotes purchasing of raw materials through the traditional channel, not depending on state, $W$ denotes purchasing on the commercial channel in state $C$, and $v_{T}$ and $v_{C}$ are levels of material input in the states $T$ and $C$, respectively.

Let us now move on to financial balances of the firm. The money deposit $\grave{I}$ (current account) varies in 
time as follows:

$\begin{array}{cc}\mathrm{d} M / \mathrm{d} t=-B_{T}+\left(q_{1}-p_{1}\right) Y-\left(q_{2}-p_{2}\right) V+K_{T}-H_{T} & \text { in } T \\ \mathrm{~d} M / \mathrm{d} t=-B_{C}+\left(q_{1}-p_{1}\right) Y-\left(q_{2}-p_{2}\right) V+K_{C}-H_{C}-q_{2} W+q_{1} Z-\varphi(Z) & \text { in } C\end{array}$

where $B_{s}$ denotes gross income of the firm in the state $s=T, C$. The gross income covers profit, wage bill, fixed expenditures, taxation and so on. $K_{s}$ and $I_{s}$ denote bank credit and debt servicing in the state $s=T, C ; q_{1}, q_{2}$ denote market prices and $p_{1}, p_{2}$ denote rates of non-payment for good sold and raw materials purchased, respectively.

Accordingly, debtors receivable $S_{A}$ and accounts payable $S_{P}$ of the firm grow as

$$
\mathrm{d} S_{A} / \mathrm{d} t=p_{1} Y ; \quad \mathrm{d} S_{P} / \mathrm{d} t=q_{2} V
$$

These relations mean that inter-firm debts are never paid off. Comparison to empirical data for 1995-1997 allows us to consider such a supposition as admissible.

Debt servicing $I_{s}$ consists of interest payments and return of previous credits, so the debts to the bank are paid off, at least partially. The dynamics of the firm's debt to the bank depend on the received mode of extra charge of interest rate and are outside the scope of this work. We simply assume as in Guriev and Pospelov (1997) that the bank crediting the firm gains the constant average interest $r$

$$
\begin{aligned}
& \tau H=(1+r)(1+\tau) K \\
& H=\mathbf{E}\left\{H_{C}-K_{C} \mid C\right\} ; K=\mathbf{E}\left\{K_{T}-H_{T} \mid T\right\}
\end{aligned}
$$

While labor is not a limiting factor of production and the investments are practically negligible, the subdivision of gross income on profit, wage bill and amortization does not influence the choice of optimum firm policy. So we assume that the firm is interested in gross income. In our model, the gross income is stochastic. As in Guriev and Pospelov (1997), we assume that the bank crediting firm is taking all risk of losses in a "poor" state $T$, as long as it is prolonged. Then it is logical to assume the firm to be risk neutral, that is to assume that it is interested in the average gross income.
Further, we will consider only the stationary case when the values of the control variables $x_{T}, x_{C}, v_{T}, v_{C}$, $Y, V, Z, W, K_{T}, H_{T}, K_{C}, H_{C}$ remain constant and phase variables $M, Q_{1}, Q_{2}$ fluctuate around their constant average values. Under these assumptions, the optimal behavior of the firm should maximize the value of average income.

$$
J=\tau B_{C}+(1-\tau) B_{T} \Rightarrow \max
$$

over control variables $x_{T}, x_{C}, v_{T}, v_{C}, Y, V, Z, W, K_{T}$, $H_{T}, K_{C}, H_{C}$ subject to constraints which may be divided into three groups.

1. Technological constraints

$$
v_{T} \geq \psi\left(x_{T}\right) ; \quad v_{C} \geq \psi\left(x_{C}\right) ; \quad x_{T} \geq 0 ; \quad x_{C} \geq 0
$$

2. Constraint of a non-negativity of the material stocks. In the stationary process, the necessary condition of non-negativity of stocks is a condition of a non-negativity of mean values of their derivatives over time.

$$
\begin{aligned}
& \tau x_{c}+(l-\tau) x_{T}-\tau Z-Y \geq 0 \\
& \quad-\tau v_{C}-(l-\tau) x_{T}+\tau W+V \geq 0
\end{aligned}
$$

Besides that, we demand that in a state $\dot{O}$ the firm fulfils its obligations on direct links with probability 1 . Since the state $\dot{O}$ may be prolonged without restriction, the necessary and sufficient conditions of fulfilling obligations are the following inequalities.

$$
x_{T} \geq Y ; \quad V \geq v_{T}
$$

We do not put such a restriction for the state $C$, considering that in a commercial condition the firm can operatively cover possible shortage of input caused by unexpectedly long functioning of the commercial channel. Of course, it causes additional expenditures. Their mean value should be accounted in the sale cost function $\varphi$.

Institutional restrictions. We exclude the possibility of selling goods for money beside trade intermediaries. This limitation is expressed by the 
following inequalities.

$$
W \geq 0 ; \quad Z \geq 0
$$

In reality, negative $W$ would mean that the firm sells raw material in the market, gaining the complete price $q_{2}$, but does not pay $\varphi(-W)$. The second transition in Eq. (7) was put in to remove the question of prolonging the function $\varphi(Z)$ on negative values. At any reasonable setting of the problem of the firm behavior, the solution $Z$ should be non-negative.

Solvency constraint. Under the assumption made above, up to now any firm would prefer to purchase raw materials $V$ through the traditional channel for non-payments and deliver its product to the market for full price. However, such a behavior would break equilibrium. We assume that the inter-firm relations imply some balance between payable and receivable accounts. A firm justifies its own non-payments to suppliers by non-payments of its consumers. In other words, accounts payable (liabilities) are ensured by accounts receivable (assets). In the model, this balance can be entered as follows:

$$
p_{2} V \leq p_{1} Y+\delta
$$

where $\delta$ is prescribed from the outside acceptable value of additional emission of the non-payments for the given firm. The most natural value for $\delta$ is 0 .

Liquidity constraint. As in the case of material stocks, the requirement that the current account will be non-negative with probability 1 for stationary process reduces to the conditions of a non-negativity of cash flows $\mathrm{d} \grave{I} / \mathrm{d} t$ in both states. Since the firm maximizes a functional Eq. (3), it is obvious that $B_{T}$ and $B_{C}$ are determined from conditions $\grave{I}=0$ in the respective states (see Eq. (1)). Thus it is necessary to demand that the gross income in both states is nonnegative $B_{T}, B_{C} \geq 0$. Since state $C$ delivers additional possibilities in comparison the state $T, B_{C}$ any rate is not less than $B_{T}$, therefore it is enough to impose a condition of non-negativity only on $B_{T}$. Using Eqs. (1) and (2), inequality $\boldsymbol{B}_{T} \geq 0$ may be rewritten as

$$
\left(q_{1}-p_{1}\right) Y-\left(q_{2}-p_{2}\right) V+K \geq 0
$$

We should also prohibit the firm from gaining money by credit from the bank. In view of Eq. (2), this means that

$$
K \geq 0
$$

So we will describe the firm's behavior as the solution of the following optimization problem

$$
\begin{aligned}
J= & \left(q_{1}-p_{1}\right) Y-\left(q_{2}-p_{2}\right) V+\tau\left(q_{1} Z-\varphi(Z)\right. \\
& \left.-q_{2} W\right)-r(l-\tau) K \\
\Rightarrow & \max
\end{aligned}
$$

subject to Eqs. (4)-(10).

Proposition 1. Let the set of admissible values of control variables not be empty *, i.e. there exists $x_{C}$, $x_{T}, v_{C}, v_{T}, Y, V, Z, W$ and $K$, satisfying Eqs. (4)-(10). Then the problem of maximization of the functional Eq. (11) over $x_{C}, x_{T}, v_{C}, v_{T}, Y, V, Z, W, K$ subject to constraints Eqs. (4)-(10) has unique finite solution. On this solution, the conditions in Eqs. (4) and (5) are fulfilled as equalities, and

$$
K=\max \left\{0,-\left(q_{1}-p_{1}\right) Y+\left(q_{2}-p_{2}\right) V\right\}
$$

We have assumed that the firm maximizes gross income at the given interest rate $r$. Let us compare this problem with the problem in which the firm has no possibility of having credit, i.e. when $K=0$ and the liquidity constraint Eq. (9) looks like

$$
\left(q_{1}-p_{1}\right) Y-\left(q_{2}-p_{2}\right) V \geq 0
$$

The problem in Eq. (11), subject to Eqs. (4)-(8) and (9), also has a unique solution. Let $\lambda$ be the Lagrange multiplier removing liquidity constraint in the problem without credit. It is easy to show (see Guriev and Pospelov, 1997) that if $r>r^{*}=$ $\lambda /(1-\tau)$, then in the initial problem, Eq. (11), subject to Eqs. (4) -(10), the firm will not have credit

* This requires harmony between fixed costs $\psi(0)$ and quota of the non-payments $\Delta$. 
$(K=0)$. For this reason, the bank will certainly not set its interest rate higher than $r^{*}$. Therefore, we will further solve the problem of behavior of the firm only at $r \in[0, r]$.

Further, it will be convenient to include the solvency constraint Eq. (8) in the functional $J$ with the Lagrange multiplier $\theta$ and consider Lagrangian

$$
\begin{aligned}
L(\theta)= & \left(q_{1}-p_{1}\right) Y-\left(q_{2}-p_{2}\right) V+\tau\left(q_{1} Z\right. \\
& \left.-\varphi(Z)-q_{2} W\right)-r(l-\tau) K+\theta\left(p_{1} Y+\delta-p_{2} V\right)
\end{aligned}
$$

According to saddle-point theorem, there exists $\theta^{*} \geq 0$ such that

$$
\max _{0} J=\max _{1} L\left(\theta^{*}\right) \leq \max _{1} L(\theta)
$$

for all

$$
\theta \geq 0
$$

where $\max _{0}$ denotes maximization over $x_{C}, x_{T}, v_{C}, V_{T}$, $Y, V, Z, W$ and $K$ subject to Eqs. (4)-(10) and $\max _{1}$ denotes maximization over the same variables subject to Eqs. (4)-(7), (9) and (10), that is without solvency constraint. When $\theta=\theta^{*}$ the solutions of problems $\max _{0} J$ and $\max _{1} L\left(\theta^{*}\right)$ coincide. The value $\theta^{*}$ may be interpreted as the inner rate of non-payments of the firm.

\section{NON-PAYMENTS AND INTEGRATION OF FIRMS}

The offered model of behavior of the firm allows us to reveal reasons for firms joining in a formal or informal FIG. By definition, the FIG carries "the joint liability over obligations". Let us consider a group $N$ of different firms, with the behavior of each described by the model stated above. Within this section, we will denote the values corresponding to different firms by superscript $j \in N$. The joint liability over obligations can be understood as a change in the individual solvency constraints $p_{2} V^{j} \leq p_{1} Y^{j}+\delta^{j}$ (see Eq. (9)) to the total one

$$
\sum_{j \in \mathbb{N}} p_{2} V^{j} \leq \sum_{j \in \mathbb{N}} p_{1} Y^{j}+\sum_{j \in \mathbb{N}} \delta^{j}
$$

It is possible to consider a problem of maximization of the aggregate gross income of the FIG $J^{N}=\sum_{j \in \mathrm{N}} J^{j}$ subject to the individual constraints in Eqs. (4)-(7), (9) and (10) and the total solvency constraint in Eq. (8). Similarly to the problems for each firm, this problem for all firms also has a unique finite solution. Let $\Theta *$ be the Lagrange multiplier to the constraint in Eq. (8) in the aggregate problem. From Eq. (14), we obtain

$$
\begin{aligned}
\max _{0} J^{N} & =\sum_{j \in \mathrm{N}} \max _{1} L^{j}\left(\Theta^{*}\right) \geq \sum_{j \in \mathrm{N}} \max _{1} L^{j}\left(\theta^{* j}\right) \\
& =\sum_{j \in \mathrm{N}} \max _{0} J^{j}
\end{aligned}
$$

This means that the gross income of the FIG exceeds the sum of their individual incomes and hence aggregation into the FIG is profitable for individual firms.

The result obtained in Eq. (15) can be interpreted as follows. We consider a firm operating in an economy with two systems of prices and accordingly with two types of money: usual money and non-payments. With the lack of an open market on which one type of money can be exchanged for another, Greshem's law does not hold, and each firm appreciates the nonpayments differently: magnitude of inner rate of nonpayments $\theta_{*}^{j}$ depends on $\tau^{j}, \psi^{j}(\cdot), \varphi^{j}(\cdot)$ etc. and they are not obliged to coincide for different firms. The totalling of solvency constraints is equivalent to organization of the local competitive market of nonpayments, on which the firms with smaller $\theta_{*}^{j}$ sell and firms with larger $\theta_{*}^{j}$ buy non-payments at the equilibrium price $\Theta *$. In the absence of such a market, non-payments (the mutual credit of firms) circulate only along technological chains. The formation of the market of non-payments allows the mutual credit to firms to spread, irrelevant to each other technologically. 
Instead of organization of the local market, it is possible to achieve the same result by reallocation of quotas on "emission" $\delta^{j}$ inside the FIG. It is enough to change $\delta^{j}$ in Eq. (8) for the firm $j \in N$ by

$$
\Delta^{j}=p_{1} Y_{*}^{j}-p_{2} V_{*}^{j}
$$

where $Y_{*}^{j}, V_{*}^{j}$ are the solutions of the problem $\max _{0}$ $J^{N}$. It is easy to prove that it is a real reallocation of quotas,

$$
\sum_{j \in \mathrm{N}} \Delta^{j}=\sum_{j \in \mathrm{N}} \delta^{j}
$$

In any case-whether by organization of the local market or by reallocation of quotas - the manager of the market (central company or bank) is necessary for the FIG. The most natural mode of reallocation of debts is the well-known financial procedure of rediscount of promissory notes by the bank, which consists of the following. The firm wishing to sell for money debt receivable, first interchanges it for the banking promissory note, which is bought by another firm (in practice, it more often is the buyer of production of the debtors). The sense of this procedure is that the banking promissory note is ensured by assets of the bank, instead of the chain of mutual nonpayments. The functions of the bank are to test and to satisfy by promissory note the actual solvency of debtor.

Actually for services in such an organization of mutually advantageous agreements, the intermediaries (in particular, the banks) raise a particular bill discount. In the model, we neglect it and assume that bank operates disinterestedly.

We speak above only of solvency constraints as in Eq. (8). Reallocations of financial flows within the FIG can also soften liquidity constraints as in Eq. (9). As it was shown in Guriev and Pospelov (1997), this can be done by assigning individual interest rates to the firms.

\section{OPTIMUM BEHAVIOR OF THE FIRM}

The above results shows that the behavior or the firm included in the FIG may be described as the solution of the following optimization problem (we again omit an index of the firm $j$ ):

$$
\begin{aligned}
J & =s_{1} Y-s_{2} V+\pi\left(q_{1} Z-\varphi(Z)-q_{2} W\right) \\
& \Rightarrow \max
\end{aligned}
$$

subject to Eqs. (4)-(7) and (9), where

$$
\begin{aligned}
& s_{1}=\left(q_{1}-p_{1}\right)(l+r(l-\tau))+\Theta^{*} \\
& \quad s_{2}=\left(q_{2}-p_{2}\right)(l+r(l-\tau))+\Theta^{*} p_{2} p_{1} ;
\end{aligned}
$$

are the effective prices of delivery and purchasing through the traditional channel, $\theta *$ is the equilibrium rate of non-payments inside the given FIG.

Proposition 2. Let cost functions $\psi(\cdot)$ and $\vartheta(\cdot)$ obey the above suppositions. Then the solution of the problem in Eq. (16) is characterized as follows.

If $s_{1} / q_{1}<1$ and $s_{2} / q_{2} \leq 1$, then $W=0, Z, x_{T}>$ $0, \quad V=v_{c}=v_{T}=\psi\left(x_{T}\right), x_{c}=x_{T}, O=x_{T}-\tau Z>$ 0 and the values of $Z, x_{T}$ are determined by the equations

$$
\varphi^{\prime}(Z)=q_{1}-s_{1}, \quad \psi\left(\tilde{o}_{T}\right) s_{1} / s_{2} .
$$

1. If $s_{1} / q_{1} \geq 1$ and $s_{2} / q_{2} \leq 1$, then $Z=W=0, O ́=x_{c}=x_{T}, V=v_{c}=v_{T}=\psi\left(x_{T}\right)$ and the value of $x_{T}$ is determined by the equation

$$
\psi^{\prime}(\tilde{o} T) s_{1} / s_{2} .
$$

2. If $s_{2} / q_{2} \geq 1$ and $s_{2} / q_{2} \geq s_{1} / q_{1}$, then $W=$ $v_{C}-v_{T}>0, Z>0, V=v_{T}, v_{C}=\psi\left(x_{C}\right)>v_{T}=$ $\psi\left(x_{T}\right), Y=x_{T}-\tau\left(Z+x_{T}-x_{C}\right)$ and the values of $Z$, $x_{C}, x_{T}$ are determined by the equations

$$
\begin{aligned}
& \varphi^{\prime}(Z)=q_{1}-t_{1}, \quad \psi^{\prime}(\tilde{o} T)=\left(s_{1}-\pi t_{1}\right) /\left(s_{2}-\tau q_{2}\right), \\
& \psi^{\prime}\left(\tilde{o}_{C}\right) t_{1} / q_{2} .
\end{aligned}
$$

Here parameter $t_{1}$ is defined by the following algorithm; if at $t_{1}=s_{1}$ the above relations give the 
values such that $Z+x_{T}-x_{C}>0$, then put $t_{1}=\mathrm{s}_{1}$, else find $t_{1}<s_{1}$ so that $Z+x_{\mathrm{T}}-x_{C}=0$.

Proposition 2 shows that the model qualitatively allows different policies of the firm. Case 1 describes the firm inside which both channels are mixed with each other. Produced goods are delivered through both channels, but all raw materials are purchased through the traditional channel only.

Case 2 corresponds to the firm using the traditional channel exclusively. Case 3 describes the firm inside which market and traditional structures coexist but are not mixed. Part of the goods directed through the traditional channel are made with raw materials purchased through the traditional channel. Part of the goods directed through the commercial channel are made with raw materials purchased for money at the market.

Investigation of the principals of firms shows that in modern Russian economy all three modes of policy are presented, but the most typical is case 1. Case 1 also is symmetric concerning relations of the prices $s_{i} / q_{i}, i=1,2$. It is possible to imagine a model economy in which all firms operate as in Case 1, delivering one part of production to each other through the traditional channel, and the other part through the commercial channel in the consumer market.

\section{References}

Avtukhovich, E.V., Guriev, S.M., et al. (1999) Mathematical Model of Regional Economy (Computer center of RAS, Moscow), in Russian.
Dologopyatova, T.G. (1995) The Russian Firms in Transitional Economy: Economic Problems and Behavior (Delo Ltd., Moscow).

Grigoriev, P. (1997) Arrears and the Structure of the Russian Economy: Industrial Organisation and Pricing Mechanisms (New Economic School, Moscow).

Grunville, Â., Pulterovich, V., Denisova and Medvedev, A. (1996) "Inflation and Recession: Preliminary Results for Russia", Prepared for the conference "Government in EconomicTransition" (GET), New Economic School, Moscow.

Guriev, S.M. and Pospelov, I.G. (1997) Model of activity of bank in lack of growth and inflation Economica and Mathematical Methods, (Moscow) vol. 33, [In Russian], p 3.

Kirn, S. and Kwon, G.A. (1995) "General Equilibrium Approach to Inter-Enterprise Arrears in Transition Economies with Application to Russia", IMF Working Papers, N.Y.

Klepach, L. (1997) Debt economy: monetary, industrial and political aspects of a problem (Voprosy Economici, Moscow), in Russian.

Makarov, V.L. and Leiner, G.B. (1997) Barter in an economy of the transition period: singularities and tendencies Economica and Mathematical Methods, (Moscow) Vol. 33, p 2.

Non-payments in Russian Economy, (1998) Brunswick Brokerage, Moscow, October 28.

Perotti, E.G. (1994) "Collusive Arrears in transition Economies", Boston University, May.

Pospelov, I.G. (1995) Model of behavior of producers in conditions of preferencial crediting Mathematical Stimulation, vol. 7, [In Russian], p 3.

Shmelev, N. (1997) The non-payments-problem number one of the Russian economy (Voprosy Economici, Moscow), in Russian, $p$ 4.

Smirnov, A.O. (1997) "Crisis of payments in energy complex: bill variant of overcoming", Problem of prognozing, (Moscow), [In Russian].

Yakovlev, A. (1996) "Industrial Enterprises in the Markets. New Market Relations, Status and Perspectives of Competiton", NASA Working Paper, WP96-W048, Vienna, May. 


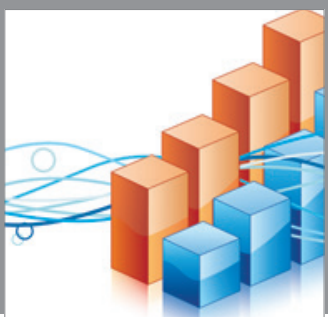

Advances in

Operations Research

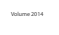

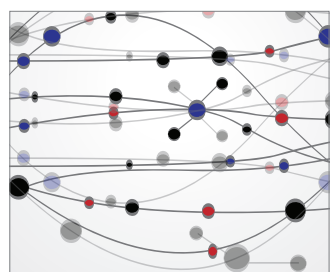

\section{The Scientific} World Journal
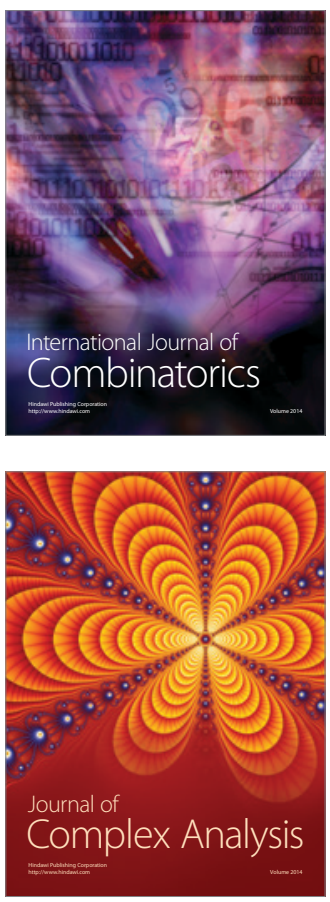

International Journal of

Mathematics and

Mathematical

Sciences
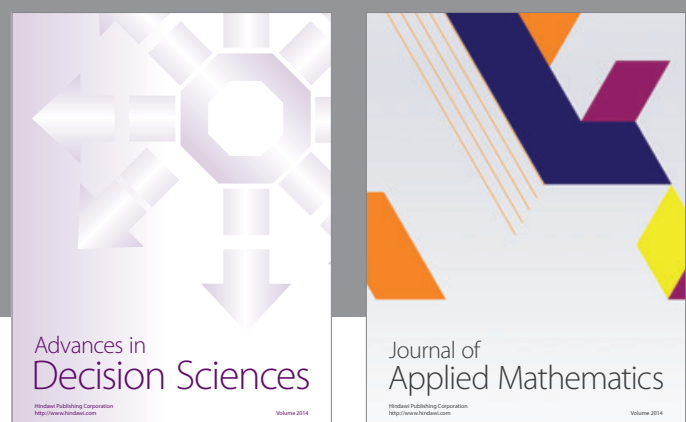

Journal of

Applied Mathematics
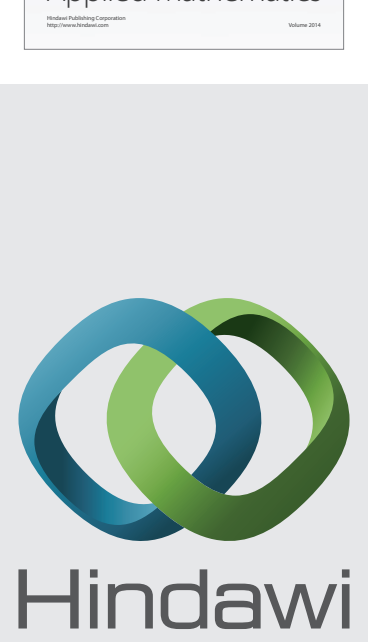

Submit your manuscripts at http://www.hindawi.com
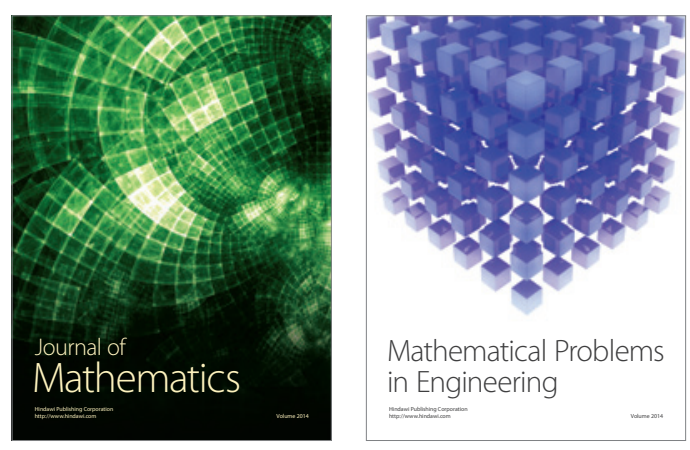

Mathematical Problems in Engineering
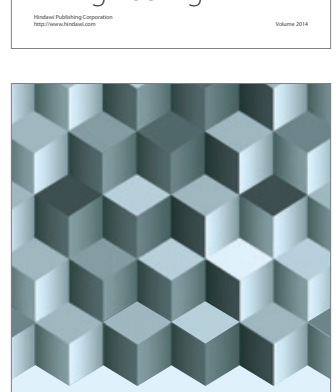

Journal of

Function Spaces
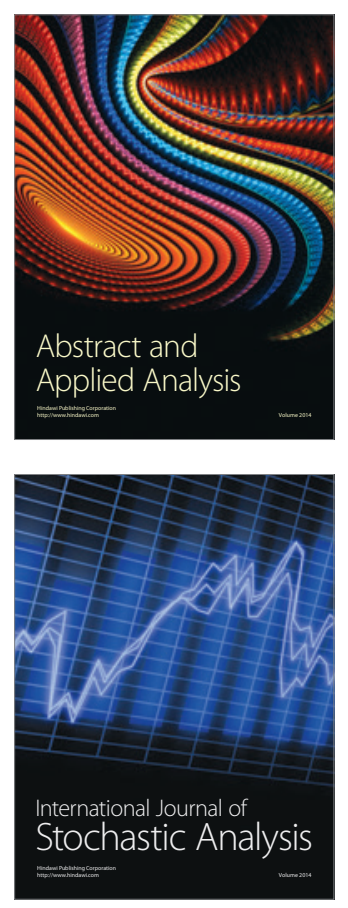

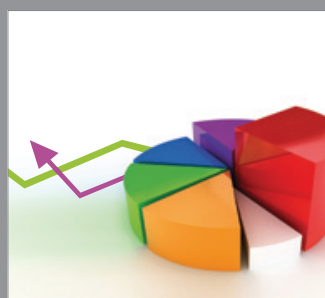

ournal of

Probability and Statistics

Promensencen
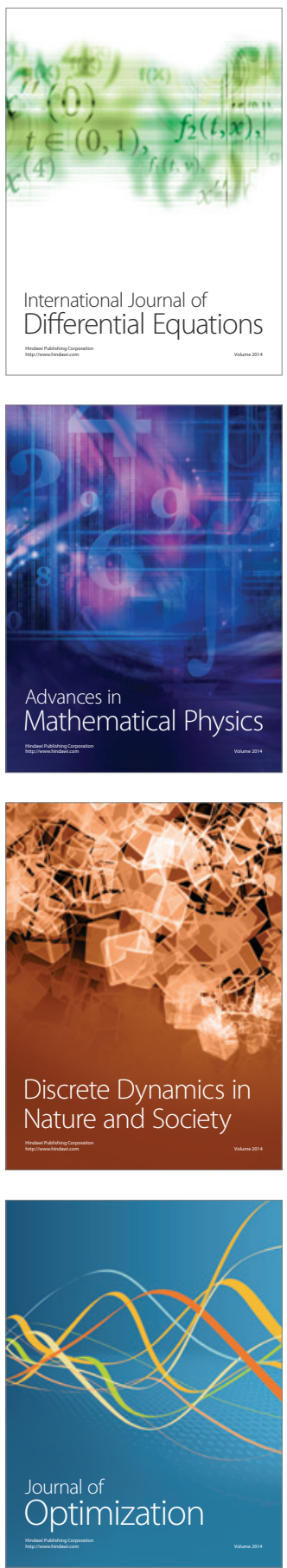